\title{
Meta-Analisis: Pengaruh Bahan Ajar Berbasis Pendekatan STEM Pada Pembelajaran Ekologi
}

\author{
Tomi Apra Santosa ${ }^{1 *}$ (D), Abdul Razak ${ }^{1}$, Lufri ${ }^{1}$, Zulyusri ${ }^{1}$ (D), Elmayana Fradila ${ }^{1}$, \\ Fitri Arsih 1 (iD \\ ${ }^{1}$ Program Studi Magister Pendidikan Biologi, Universitas Negeri Padang, Indonesia \\ Jalan Prof. Dr. Hamka, Air Tawar, Padang, 25132, Sumatera Barat \\ *Corresponding author: santosatomiapra@gmail.com
}

\begin{abstract}
Abstrak: Tujuan penelitian ini untuk menganalisis pengaruh bahan ajar ekologi berbasis pendekatan STEM terhadap pembelajaran Abad-21. Metode penelitian ini adalah meta-analisis dengan menelaah sumber data yang berasal dari jurnal nasional atau internasional terbitan empat tahun terakhir (2016-2020). Hasil penelitian menunjukan bahwa studi meta-analisis berpengaruh pada bahan ajar ekologi berdasarkan pendekatan STEM berdasarkan tingkat pendidikan, jenis media yang digunakan, dan pendekatan STEM dalam pembelajaran ekologi. Temuan penelitian menunjukkan bahwa pengaruh bahan ajar ekologi berdasarkan pendekatan ilmiah memiliki harga rata-rata lebih tinggi di tingkat SMA dibandingkan dengan sekolah dasar dan menengah pertama. Harga ukuran efek rata-rata untuk tingkat pendidikan menengah atas, menengah pertama dan dasar adalah: 1,63; 1,56; dan 1,19 pada kategori tinggi. Sedangkan dari segi media pembelajaran akan lebih efektif jika diaplikasikan dalam modul, dibandingkan dengan media lain, rata-rata effect size modul, LKS/LKPD, dan bahan ajar masing-masing adalah: 2,05; 1,14; dan 0,62 pada kategori tinggi. Berdasarkan hasil belajar kognitif dan keterampilan siswa, pengaruh harga rata-rata terhadap effect size proses sains, hasil belajar, berpikir kritis, dan pemecahan masalah adalah 1,32; 1,61; 2.32; dan 1.83 dengan kategori tinggi maka diikuti kompetensi siswa dengan memberikan pengaruh pada kategori sedang yaitu: 0,61 .
\end{abstract}

Kata Kunci: Bahan Ajar, Pendekatan STEM, Ekologi

Abstract: The purpose of this study was to analyze the effect of ecology teaching materials based on the STEM approach on 21st-century learning. This research method is a meta-analysis by examining data sources from national or international journals published in the last four years (2016-2020). The results showed that the meta-analysis study affected ecology teaching materials based on the STEM approach based on the level of education, the type of media used, and the STEM approach in ecological learning. The research findings showed that the effect size of ecological teaching materialbased on scientific approach has a higher average prize at senior secondary level compared to primary and junior secondary. The average effect size prices for senior secondary, junior secondary, and primary education levels were: 1.63; 1.56; and 1.19 in the high category. Meanwhile, in terms of learning media, it will be more effective if applied in modules, compared to other media, the average effect size of the module, student worksheet, and teaching materials respectively are: 2.05; 1.14; and 0.62 in the high category. Based on students' cognitive learning outcomes and skills, the effect of the average price on the effect size of the science process, learning outcomes, critical thinking, and problem-solving was 1.32; 1.61; 2.32; and 1.83 with the high category, followed by student competence by giving influence to the medium category, namely: 0.61.

Keywords: Teaching Materials, STEM, ecology

\section{PENDAHULUAN}

Sumber Daya Manusia (SDM) menjadi indikator utama berhasilnya pendidikan. Pendidikan yang baik akan menghasilkan sumber daya manusia yang unggul dan kompetitif, 
serta mampu memecahkan berbagai permasalahan (Salim, 2014). Pada dasarnya pendidikan adalah usaha sadar manusia untuk menumbuh kembangkan potensi peserta didik dengan cara mendorong dan memfasilitasi peserta didik dalam proses belajar. Belajar merupakan proses perubahan perilaku yang berkaitan dengan kognitif, afektif dan keterampilan untuk menjadi lebih baik. Sementara itu, pembelajaran yaitu suatu usaha sadar untuk melaksanakan kegiatan belajar mengajar antara pendidik dan peserta didik. Dalam proses belajar mengajar yang terlibat aktif adalah guru dan peserta didik (Sumiati et al., 2018; Heru \& Hidayati, 2017).

Pembelajaran yang diterapkan pada kurikulum 2013 menumbuhkan keterampilan kognitif, afektif dan psikomotor (Asrizal et al., 2018). Salah satunya adalah pembelajaran ekologi. Pembelajaran ekologi diarahkan untuk mencari tahu dan berbuat, sehingga dapat membantu siswa untuk memperoleh pemahaman dan pengetahuan yang berkaitan dengan alam.

Pada Undang-Undang RI Nomor 20 Tahun 2003, tujuan pendidikan yaitu untuk mengembangkan potensi peserta didik agar menjadi manusia yang beriman dan bertakwa kepada Tuhan Yang Maha Esa, berakhlak mulia, sehat, berilmu, cakap, kreatif, mandiri, dan menjadi warga negara yang demokratis serta bertanggung jawab dalam pelaksanaan kegiatan pendidikan (Vitasari \& Rohayati, 2018). Usaha yang dapat dilakukan pemerintah untuk mencapai tujuan pendidikan adalah peningkatan mutu pendidikan melalui pengadaan buku ajar maupun penyempurnaan kurikulum (Festiyed, 2014). Agar dapat mencapai tujuan pendidikan, maka diperlukan bahan ajar yang mampu mengembangkan peserta didik dalam mencapai kemampuan berfikir kritis dalam memecahkan suatu masalah.

Bahan ajar adalah sebuah alat yang dirancang secara sadar dan sistematis yang digunakan guru untuk mempermudah menyampaikan informasi sehingga tercapainya kompetensi peserta didik dalam proses pembelajaran. Bahan ajar juga dapat membantu peserta didik dalam belajar, seperti modul, LKS, buku, dan lain-lain. Penggunaan bahan ajar diperlukan dalam proses pembelajaran agar mampu mencapai tujuan pembelajaran. Dengan adanya bahan ajar diharapkan dapat meningkatkan keaktifan siswa, pemahaman siswa dan meningkatkan kreativitas siswa serta membuat materi dekat dengan kehidupan siswa.

Untuk dapat mencapai tujuan pembelajaran dibutuhkan pendekatan yang sesuai dengan kurikulum 2013 dan mampu mencapai tujuan pembelajaran tersebut. Salah satunya adalah dengan pendekatan saintifik (Rahayu et.al, 2019). Pendekatan STEM adalah sistem pembelajaran yang dapat melatih siswa mampu dalam memecahkan suatu masalah yang berkaitan dengan kegiatan belajar mengajar. Dalam pembelajaran siswa harus mampu terlibat aktif dalam proses pembelajaran yang terjadi di dalam kelas.

Kondisi yang terjadi sekarang terlihat bahwa dalam kegiatan pembelajaran yang berorientasi pada pendidik (teacher centered) menjadikan peserta didik tidak berpartisipasi aktif. Seperti dalam pembelajaran fisika, guru cenderung memberikan contoh yang abstrak. Siswa tidak dapat membayangkan dan mengaplikasikannya. Hal ini menyebabkan persepsi siswa mengenai mata pelajaran fisika itu sulit untuk dipahami. Sebenarnya, fisika itu mudah dan menarik, karena kasus-kasus dalam fisika pada umumnya kita pernah mengalami dalam kehidupan sehari-hari. Guru bisa mengaitkan konsep-konsep fisika dengan kejadian sehari-hari yang dialami siswa sehingga siswa bisa membayangkan dan mengalami langsung konsepkonsep tersebut. Jika siswa mengalami langsung atau mempraktekkan langsung suatu konsep fisika, siswa akan mudah mengerti dan memahami konsep tersebut. Pembelajaran ialah suatu cara yang terjadi antara siswa dan guru agar mampu melakukan kegiatan belajar di kelas (Rahman et al., 2020).

Pada kurikulum 2013 menyatakan bahwa guru sebagai fasilitator dapat menyediakan berbagai sumber belajar baik dirancang sendiri maupun yang telah disediakan pemerintah. Bahan ajar dibutuhkan untuk melakukan kegiatan belajar mengajar sebagai penunjang agar proses pembelajaran dapat terarah. Bahan ajar dirancang sebagai alat yang dapat membantu guru dan siswa untuk pembelajaran yang lebih efektif (Asrizal et.al.,2018; Marsa et.al., 2016). Guru harus memfasilitasi peserta didik agar konsep fisika yang diajarkan dipahami oleh siswa. 
Dengan memahami konsep, siswa bisa menganalisa soal-soal latihan yang berbeda dengan contoh soal. Solusinya yaitu guru bisa menggunakan bahan ajar yang menuntun siswa untuk belajar. Bahan ajar mampu mendorong siswa dalam memahami konsep atau materi pelajaran yang efektif (Hardianti et al., 2020).

Penelitian sebelumnya penggunaan bahan ajar yang berbasis saintifik berpengaruh terhadap kompetensi dan ketrampilan peserta didik (Yenni et al., 2020). Bahan ajar juga dapat meningkatkan penguasaan konsep pelajaran pada siswa (Oktaviani et al., 2017). Pendekatan saintifik mempunyai pengaruh terhadap aspek kognitif, afektif, dan psikomotorik peserta didik (Machin, 2014). Penelitian ini adalah penelitian meta-analisis bertujuan untuk mengukur besarnya effect size dari pegaruh bahan ajar berbasis pendekatan saintifik IPA dan Fisika berdasarkan tingkatan pendidikan, jenis media yang digunakan, hasil belajar kognitif dan keterampilan siswa.

\section{METODE PENELITIAN}

Penelitian ini adalah jenis penelitian meta-analisis. Sumber data berasal dari jurnal nasional atau internasional empat tahun terakhir. Teknik pengumpulan data yaitu dengan menelaah atau menelusuri sumber yang berasal dari jurnal nasional atau internasional yang terbitan empat tahun terakhir (2016-2020) melalui database Eric, Google Scholar, Moraref, ScienceDirect, IEEE dan Wiley of Taylor. Penelitian meta-analisis ini menggunakan jurnal yang berkaitan dengan semua jenis bahan ajar berbasis pendekatan STEM pada pembelajaran ekologi, dimana jumlah artikel yang dianalisis terdiri dari 10 artikel. Setelah itu, akan dilihat effect size dari masing-masing artikel yang diperoleh dengan menggunakan rumus yang ada pada Tabel 1.

Tabel 1. Perhitungan Effect Size

\begin{tabular}{|c|c|c|}
\hline No & Data Statistik & Rumus \\
\hline 1 & $\begin{array}{l}\text { Rata-rata pada } \\
\text { satu kelompok }\end{array}$ & $E S=\frac{\bar{X}_{\text {post }}-\bar{X}_{\text {pre }}}{S D_{\text {pre }}}$ \\
\hline 2 & $\begin{array}{l}\text { Rata-rata pada } \\
\text { masing-masing } \\
\text { kelompok }\end{array}$ & $E S=\frac{\bar{X}_{\text {eksperimen }}-\bar{X}_{\text {kontrol }}}{S D_{\text {kontrol }}}$ \\
\hline 3 & $\begin{array}{l}\text { Rata-rata pada } \\
\text { masing-masing } \\
\text { kelompok }\end{array}$ & $=\frac{\left(\bar{X}_{\text {post }}-\bar{X}_{\text {pre }}\right)_{\text {eksperimen }}-\left(\bar{X}_{\text {post }}-\bar{X}_{\text {pre }}\right)_{\text {kontrol }}}{\left(\frac{S D_{\text {pre kontrol }}+S D_{\text {pre eksperimen }}+S D_{\text {post kontrol }}}{3}\right)}$ \\
\hline 4 & Chi-square & $E S=\frac{2 r}{\sqrt{1-r^{2}}} ; r=\sqrt{\frac{\chi^{2}}{n}}$ \\
\hline \multirow[t]{2}{*}{5} & t hitung & \multirow{2}{*}{$E S=t \sqrt{\frac{1}{n_{\text {eksperimen }}}}+\frac{1}{n_{\text {kontrol }}}$} \\
\hline & & \\
\hline 6 & Nilai P & CMA (Comperhensive Meta Analisis Software) \\
\hline
\end{tabular}

(Sumber:Ellis, 2010) 
Setelah diperoleh effect size, maka hasilnya dapat diinterpretasikan kedalam kategori pada Tabel 2.

Tabel 2. Klasifikasi Effect size

\begin{tabular}{cc} 
Effect size & Kategori Standar \\
\hline $0 \leq \mathrm{ES} \leq 0,2$ & Rendah \\
$0,2 \leq \mathrm{ES} \leq 0,8$ & Sedang \\
$\mathrm{ES} \geq 0,8$ & Tinggi \\
\hline (Sumber: Cohen, 1988) &
\end{tabular}

\section{HASIL DAN PEMBAHASAN}

1. Pengaruh Bahan Ajar Berbasis Pendekatan STEM Berdasarkan Tingkatan Pendidikan

Analisis besar pengaruh bahan ajar ekologi, berbasis pendekatan STEM berdasarkan tingkatan pendidikan yang digunakan dapat dilihat Tabel 3 berikut.

Tabel 3. Meta-analisis berdasarkan jurnal dan tahun terbit

\begin{tabular}{cccc}
\hline No & Peneliti & Jurnal & Terbit \\
\hline 1 & Hasanah, et al & Nasional & 2020 \\
2 & Zulaiha \& Kusuma & Nasional & 2020 \\
3 & Gardner, et al & Internasional & 2016 \\
4 & Thahir, et al & Internasional & 2019 \\
5 & Widarti, et al & Nasional & 2019 \\
6 & Belser, et al & Internasional & 2018 \\
7 & Ismail, et al & Nasional & 2016 \\
8 & Santoso \& Mosik & Nasional & 2019 \\
9 & Widayoko, et al & Nasional & 2018 \\
10 & Nessa, et al & Nasional & 2017 \\
\hline-
\end{tabular}

Tabel 4. Meta-analisis berdasarkan jenis penelitian

\begin{tabular}{ccc} 
No & Jenis Penelitian & Frekuensi \\
\hline 1 & Kuantitatif & 2 \\
2 & Eksperimen & 5 \\
3 & R\&D & 3 \\
\hline$-י-\cdots$
\end{tabular}

Tabel 3 menggambarkan bahwa dari hasil meta-analisis jurnal terdapat 7 jurnal nasional dan 3 jurnal internasional terbitan tahun 2016-2020. Selain itu pada Tabel 4 menjelaskan bahwa terdapat 2 jenis penelitian kuantitatif, 5 jenis penelitian eksperimen, dan 3 jenis penelitian R\&D. Akan tetapi meta-analisis juga diihat berdasarkan pada tingkat pendidikan hal ini dapat dilihat pada Tabel 5 berikut. 
Tabel 5. Meta-analisis berdasarkan tingkatan pendidikan dan effect size

\begin{tabular}{ccc} 
No & Tingkatan Pendidikan & Effect Size \\
\hline 1 & SD & 1,19 \\
2 & SMP & 1,56 \\
3 & SMA & 1,13 \\
\hline
\end{tabular}

Berdasarkan Tabel 5 di atas, pengaruh bahan ajar berbasis pendekatan STEM berdasarkan tingkatan pendidikan SMA, SMP, dan SD diperoleh harga rata-rata Effect Size berturut-turut yaitu: 1,13; 1,56; dan 1,19 dengan kategori tinggi. Dalam artikel terdapat enam harga Effect Size dengan kategori sedang yaitu empat pada tingkat SMA dan dua tingkat SMP dan SD dalam rentang 0,49 sampai 0,79. Berdasarkan harga Effect Size yang diperoleh terlihat bahwa harga Effect Size pada tingkat SMA lebih tinggi dari pada tingkat SMP dan SD. Dari hasil dapat disimpulkan bahwa ada pengaruh bahan ajar ekologi berbasis pendekatan STEM berdasarkan tingkatan pendidikan yang digunakan. Pembelajaran saintifik ialah suatu pembelajaran yang mana siswa mampu melakukan pengamatan, bertanya, menyajikan informasi kemudian mengenalisis untuk menarik suatu kesimpulan (Alamsyah, 2016). Pembelajaran sains juga mampu mendorong tingkat sosial siswa dengan lingkungan sekitarnya (Suswandari et.al., 2020). Siswa yang memiliki kemampuan yang tinggi baik bidang kognitif maupun sosial akan mampu menghadapi berbagai macam permasalahan yang terjadi dalam kehidupannya.

\section{Pengaruh Bahan Ajar Berbasis Pendekatan STEM Berdasarkan Media yang digunakan}

Analisis besar pengaruh bahan ajar ekologi yang berbasis pada pendekatan STEM berdasarkan media yang digunakan dapat dapat dilihat pada Gambar 1 dibawah ini.

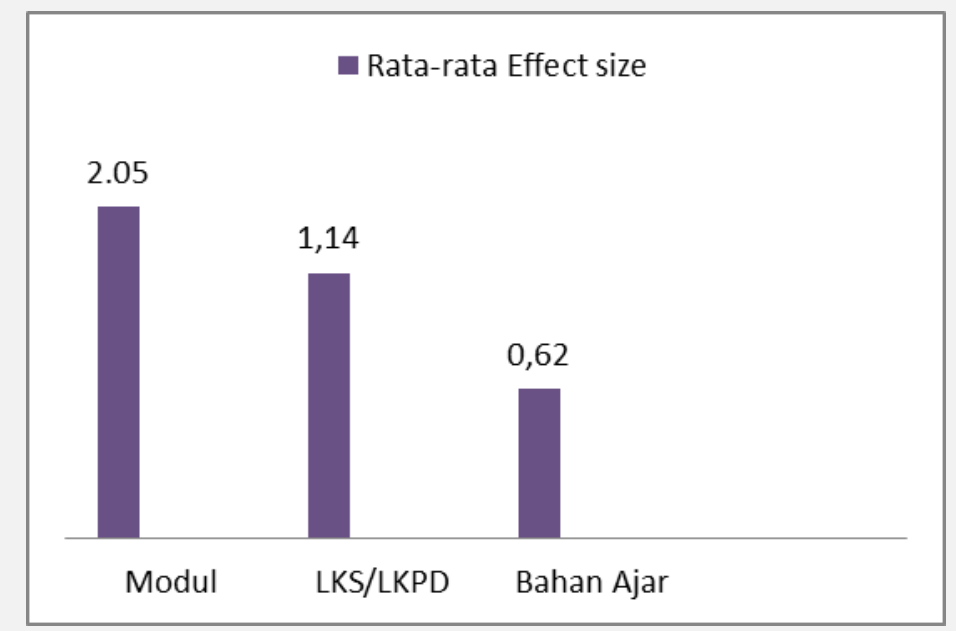

Gambar 1. Rata-Rata Effect Size Berdasarkan Media

Dari meta analisis pengaruh bahan ajar ekologi berbasis pendekatan saintifik berdasarkan media yang digunakan dalam pembelalajaran ekologi diperoleh harga rata-rata Effect Size untuk modul, LKS/ LKPD, dan bahan ajar berturut-turut yaitu: 2,05; 1,14; dan 0,62 dengan kategori tinggi. Berdasarkan harga rata-rata Effect Size yang diperoleh dapat diambil kesimpulan media pembelajaran berpengaruh terhadap hasil Effect Size yang 
diperoleh, modul memiliki kategori tinggi dibandingkan media yang lain. Pendekatan STEM melaui media pembelajaran mampu mendorong hasil belajar siswa (Diani, 2016). Dalam pembelajaran diharapkan siswa mampu mengepalikasikan ilmu yang telah dipelajari (Widodo, 2017). Selain itu, penggunaan bahan ajar ekologi oleh guru akan memberikan pengaruh yang terhadap hasil belajar siswa. Bahan ajar ekologi adalah segala materi pelajaran yang telah disusun secara sistematis yang bisa digunakan oleh guru untuk melakukan proses pembelajaran di kelas (Nilasari et al., 2020).

\section{Pengaruh Bahan Ajar Berbasis Pendekatan STEM Terhadap Pembelajaran Ekologi}

Analisis pengaruh bahan ajar ekologi yang berbasis pendekatan STEM terhadap pembelajaran ekologi disajikan dalam Gambar 2 berikut.

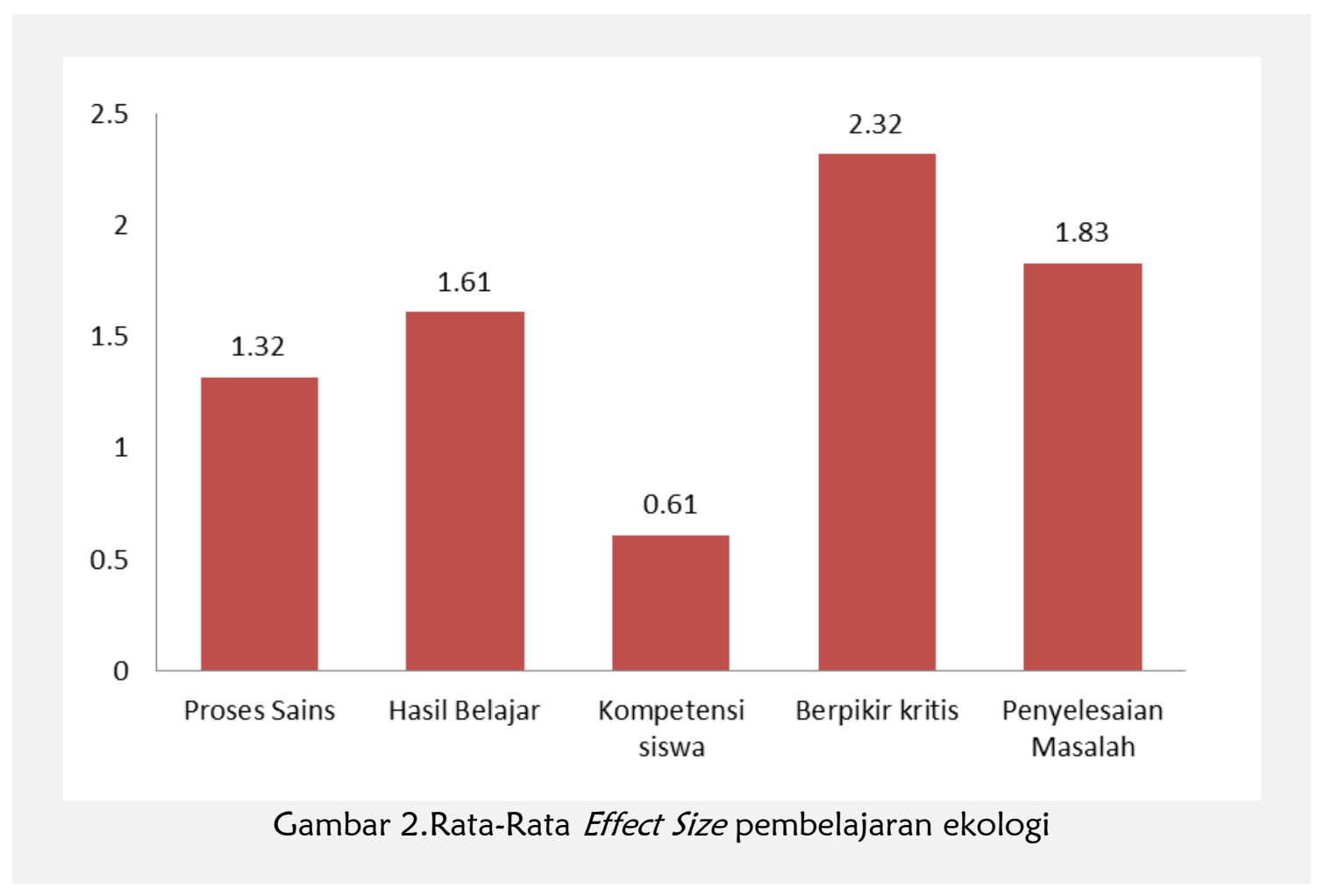

Berdasarkan Gambar 2 di atas, pengaruh bahan ajar ekologi berbasis pendekatan STEM terhadap pembelajaran ekologi siswa memberikan pengaruh terhadap harga rata-rata Effect Size proses sains, hasil belajar, berfikir kritis, dan penyelesaian masalah berturut-turut yaitu: 1,$32 ; 1,61 ; 2,32$; dan 1,83. dengan kategori tinggi, kemudian diikuti dengan kompetensi siswa dengan menyumbang pengaruh dalam kategori sedang yaitu: 0,61. Hal ini sesuai dengan tujuan dari pedekatan STEM, yakni mendorong pengetahuan siswa untuk berpikir kritis (Puspitasari et.al., 2015). Kegiatan pembelajaran ekologi yang efektif akan mampu mendorong siswa yang unggul dan berkarakter (Ulandar et.al., 2013), serta mampu meningkatkan pemahaman siswa terhadap materi pembelajaran (Andika et.al., 2020; Tamaela, 2016). Pendekatan sangat baik digunakan dalam meningkatkan hasil belajar siswa di dalam kelas (Putra et.al., 2020). Dengan demikian, penggunaan bahan yang berbasis STEM sangat cocok diterapkan pada tingkat sekolah dasar dan menengah.

\section{KESIMPULAN}

Dalam penelitian di atas dapat disimpulkan bahwa pengaruh bahan ajar ekologi berbasis pendekatan STEM akan lebih efektif jika digunakan pada tingkat SMA dan SMP, dibanding tingkat SD dengan harga rata-rata Effect Size tingkat pendidikan SMA, SMP dan SD 
berturut-turut yaitu: 1,$13 ; 1,56$; dan 1,19 dengan kategori tinggi karena pada tingkat SD tersebut kemampuan dalam mempelajari hal baru pada siswa sedang berkembang. Sementara dari subjek media akan lebih efektif jika diaplikasikan dalam modul, dibandingkan dengan media yang lain dalam pembelalajaran diperoleh harga rata-rata Effect Size untuk modul, LKS/ LKPD, dan bahan ajar berturut-turut yaitu: 2,05; 1,14; dan 0,62 dengan kategori tinggi. Berdasarkan hasil belajar kognitif dan keterampilan siswa memberikan pengaruh terhadap harga rata-rata Effect Size proses sains, hasil belajar, berfikir kritis, dan penyelesaian masalah berturut-turut yaitu 1,$32 ; 1,61 ; 2,32$; dan 1,83. dengan kategori tinggi, kemudian diikuti dengan kompetensi siswa dengan menyumbang pengaruh dalam kategori sedang yaitu: 0,61. Hal ini menunjukkan bahwa keterampilan berpikir kritis siswa setelah mengikuti proses pembelajaran menggunakan modul berbasis pendekatan STEM mengalami peningkatan yang signifikan.

\section{UCAPAN TERIMA KASIH}

Peneliti mengucapkan terima kepada Dr. Abdul Razak, M.Si ketua prodi Pendidikan Biologi pascasarjana Universitas Negeri Padang yang telah memberikan bantuan baik materi maupun nonmateri. Selain itu, peneliti mengucapkan terima kasih kepada Prof. Dr. Lufri, MS, Dr. Zulyusri, MP, dan Dr. Fitri Arsih, M.Pd yang telah membimbing dan membantu penulisan menyelesaikan penelitian ini.

\section{DAFTAR PUSTAKA}

Alamsyah, N. (2016). Penerapan Pendekatan Saintifik Untuk Meningkatkan Kreativitas dan Hasil Belajar Siswa Dalam Mata Pelajaran IPA. Jurnal Pendidikan, 1(5), 81-88. http://dx.doi.org/10.26740/jp.v1n1.p82-96

Amran, A., Purwani, L. D., \& Sudargo, F. (2018). Effectiveness of Adaptive Contextual Learning Model of Integrated Science by Integrating Digital Age Literacy on Grade VIII Students Effectiveness of Adaptive Contextual Learning Model of Integrated Science by Integrating Digital Age Literacy on Grade VII. IOP Conference Series: Materials Science and Engineering, 1-19. https://doi.org/10.1088/1757-899X/335/1/012067

Andika, F., Pramudya, I. \& Subanti, S. (2020). Problem Posing and Problem Solving With Scientific Approach In Geometry Learning. International Online Journal of Education and Teaching (IOJET), 7(4), 1635-1642.

Asrizal, Hendri, A., Hidayati, F. (2018). Penerapan Model Pembelajaran Penemuan Mengintegrasikan Laboratorium Virtual dan Hots untuk Meningkatkan Hasil Pembelajaran Siswa. Prosiding Seminar Nasional Hibah Program Penugasan Dosen Ke Sekolah (PDS), November, 49-57.

Diani, R. (2016). Pengaruh Pendekatan Saintifik Berbantukan LKS Terhadap Hasil Belajar Fisika Peserta Didik Kelas XI SMA Perintis 1 Bandar Lampung. Jurnal Ilmiah Pendidikan Fisika, 05(April), 83-93. https://doi.org/10.24042/jpifalbiruni.v5i1.108

Ellis, P. D. (2010). The Essential Guide to Effect Sizes. Cambridge University Press.

Festiyed. (2014). Pengembangan Generic Life Skill Siswa Sekolah Menengah Pertama. Seminar Nasional Dan Rapat Tahunan Bidang MIPA, 8-9. 
Hardianti, T., Pohan, L. A., \& Maulina, J. (2020). Bahan Ajar Berbasis Saintifik: Pengaruhnya Pada Kemampuan Berpikir Kritis dan Keterampilan Proses Sains Siswa SMP An-Nizam. JIPVA (Jurnal Pendidikan IPA Veteran), 4(1), 2020. https://doi.org/10.31331/jipva.v4i1.1081

Khozizah, K., Kurniawan, A. D., Rahayu, H. M. (2019). Pembelajaran IPA Menggunakan Sumber Daya Alam (SDA) Lokal Melalui Pendekatan Saintifik Berbasis Lesson Study Terhadap Hasil Belajar dan Retensi Siswa Di SMP Negeri 1 Anjungan. Pena Kreatif: Jurnal Pendidikan, 8(April), 43-60. http://dx.doi.org/10.29406/ipk.v8i1.1779

Machin, A. (2014). Implementasi Pendekatan Saintifik, Penanaman Karakter dan Konservasi Pada Pembelajaran Materi Pertumbuhan. Jurnal Pendidikan IPA Indonesia, 3(1), 28-35. https://doi.org/10.15294/jpii.v3i1.2898

Nilasari, D., Sari, L. P., \& Siregar, L. H. (2020). Pengaruh Penerapan Bahan Ajar Fisika Berbasis Pendekatan Saintifik Terhadap Kompetensi Siswa Kelas XI IPA. Jurnal PhysEdu Pendidikan, 2(1), 39-46.

Oktaviani, W., Studi, P., \& Fisika, P. (2017). Pengembangan Bahan Ajar Fisika Kontekstual Untuk Meningkatkan Penguasaan Konsep Siswa. Jurnal Pendidikan Fisika Dan Teknolog, III(1), 1-7.

Puspitasari, Y. D., Suparmi, S., Aminah, N. S. (2015). Pengembangan Modul Fisika Berbasis Scientific Pada Materi Fluida Statis Untuk Meningkatkan Keterampilan Berpikir Kritis. INKUIRI: Jurnal Pendidikan IPA, 4(2), 19-28. https://doi.org/10.20961/inkuiri.v4i2.9540

Putra, H. D., Herman, T., Sumarmo, U. (2020). The Impact of Scientific Approach and WhatIf-Not Strategy Utilization towards Student's Mathematical Problem Posing Ability. International Journal of Instruction, 13(1), 669-684. http://dx.doi.org/10.29333/iji.2020.13143a

Rahman, R., Kondoy, E., \& Hasrin, A. (2020). Penggunaan Aplikasi Quizziz Sebagai Media Pemberian Kuis Dalam Meningkatkan Motivasi Belajar Mahasiswa. Jurnal IImu Sosial Dan Pendidikan, 4(3), 60-66. http://dx.doi.org/10.36312/jisip.v4i3.1161

Salim, A. (2014). The Effect of Using Socio-Scientific Issues Approach in Teaching Environmental Issues on Improving the Students' Ability of Making Appropriate Decisions Towards These Issues. International Education Studies; 7(8), 113-123. https://doi.org/10.5539/ies.v7n8p113

Sumiati, E., Septian, D., \& Faizah, F. (2018). Pengembangan modul fisika berbasis Scientific Approach untuk meningkatkan Keterampilan Proses Sains siswa Development of Scientific Approach-based physics modules to improve students' Science Process Skills. Jurnal Pendidikan Fisika Dan Keilmuan (JPFK), 4(2), 75-88. https://doi.org/10.2572/jpfk.v4i2.2535

Suswandari, M., Siswandari, Gunarhadi. (2020). Social Skills for Primary School Students: Needs Analysis to Implement the Scientific Approach Based Curriculum. Journal of Social Studies Education Research, 11(1), 153-162.

Ulandari, F. S., Wahyuni, S., Bachtiar, R. W. (2013). Pengembangan modul berbasis saintifik untuk melatih kemampuan berpikir kritis pada materi gerak harmonis di SMAN Balung. Jurnal Pembelajaran Fisika, 7(1), 15-21. https://doi.org/10.19184/jpf.v7i1.7220

Vitasari, D., Rohayati, S.. (2018). Pengembangan Lembar Kegiatan Peserta Didik (LKPD) Berbasis Pendekatan Saintifik Pada Mata Pelajaran Administrasi Pajak Kelas XI Di SMK 
Negeri Mojoagung Pengembangan Lembar Kegiatan Peserta Didik ( LKPD ) Berbasis Pendekatan Saintifik Pada Mata Pelajaran. Jurnal Pendidikan Akuntansi, 6(2), 177-182.

Widodo, S. (2017). Pengembangan Lembar Kegiatan Peserta Didik (LKPD) berbasis Pendekatan Saintifik untuk Meningkatkan Keterampilan Penyelesaian Masalah Lingkungan Sekitar Peserta Didik di Sekolah Dasar. Jurnal Pendidikan IImu Sosial, 26(2), 189-204. https://doi.org/10.17509/jpis.v26i2.2270 